\title{
Notas sobre dez fotografias de Tete Silva, as imagens e nós
}

\author{
Marcelo Carvalho* \\ Tete Silva**
}

Tenho sob meus olhos algumas fotografias. Elas exigem, num primeiro contato, um esforço de localização, parecem escapar das coordenadas cartesianas, confundir o olhar. São conjuntos de imagens ora capturados em enquadramentos fechados, ora tomados em flagrantes desenquadramentos. Leio em cada fotografia uma busca formal que flerta com a desterritorialização, mas que ainda guarda pedaços identificáveis de objetos e lugares: roupas, cartazes, um estandarte, seções de prédios, uma escadaria, flores, água, coisas de uso profano e sagrado, criações humanas e intromissões da natureza - fundos de imagem, mas também primeiros planos obsedantes. Entre a moldura rígida da cidade e a maleabilidade dos tecidos, identifico, aqui e ali, partes de corpos, sobretudo mãos, cabeças e faces. Negras, certamente. Algo naqueles corpos se conservou, memória de mundo, palimpsesto visual que dá a conhecer sobre sua ancestralidade, sobre povos formadores invocados para a sublevação, para a guerra - blocos de sensações, como diriam certos filósofos, toda uma virtualidade composta por afectos e perceptos (DELEUZE, GUATTARI, 1992). São instantes captados nas ruas, não posados e que flagram algo. Mas, o quê? Habitam a fronteira entre a rua e um lugar indeterminado, e apesar da concretude com que essas fotografias lidam com os elementos enquadrados, uma espantosa subjetividade da fotógrafa acaba por imprimir-se, dissipando parte da atmosfera geral (histórica,

\footnotetext{
* Pós-doutorando e pesquisador associado ao grupo de pesquisa Grudes do PPGCom da UTP. Doutor e mestre em Comunicação e Cultura pelo PPGCom da ECO/UFRJ. Especialista em Arte e Filosofia pela PUC-Rio. Bacharel em Cinema e em Jornalismo pela UFF. Autor de vários capítulos de livros e artigos em revistas científicas. Atua nas áreas de comunicação, estudos de imagem, filosofia e cinema. E-mail: marcelocarvalho.0001@yahoo.com.br. ** Graduada em Psicologia, a fotografia entrou em minha vida durante meu terceiro ano de faculdade. Um desvio de percurso me levou a experimentar cerâmica (por um curto período) e gravura (por um período mais longo), o que resultou em uma exposição individual. Outras exposições coletivas vieram, tanto com gravura quanto com fotografia, no Brasil e no exterior. Fui finalista na Prix Photo Web Aliança Francesa em 2014, no 7º Euroclick em 2015 e no Observations Street Photography Festival na Alemanhã em 2017. Possuo trabalhos em publicações e coleções (Museu da Imagem e do Som de Santa Catarina e de Campinas; Museo Municipal de Artes Plásticas de Rivera, Uruguai; Centro de Cultura e Informações de Brno, República Tcheca; HistoryMiami Museum, etc.). Sou membro do Negras[fotos]grafias - coletivo de fotógrafas negras e do Flanares - um coletivo de fotógrafos brasileiros dedicado a fotografia de rua. E-mail: tete.silva@gmail.com.
} 


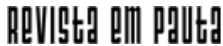

\} NOTAS SOBRE DEZ FOTOGRAFIAS - CARVALHO, M.; SILVA, T. \}

DOI: $10.12957 /$ REP.2020.47195

cultural e moral - o studium) e também sem direcionar-me para qualquer detalhe que carreasse todo o conjunto em direção a uma perdição afetiva e contundente (o punctum) (BARTHES, 2000). Ao contrário, as imagens me remetem, nesse primeiro contato, a uma espacialidade de errância, materialidade que se impõe ao olhar, tanto quanto a uma vivência espectatorial próxima à deriva.

Mas, o que é isso, a imagem? Ou ainda, o que alcançaríamos caso procurássemos o fundamento material das imagens? Uma concepção corrente reconhece na imagem uma artesania humana, ora religiosa (a estatuária com objetivo de culto), ora artística (a pintura, o desenho etc.), ora o resultado de um aparato óptico-mecânico de captação e impressão da luz em um material sensível, como no caso do cinema ou da fotografia analógica. Por imagens também são comumente reconhecidas as interfaces digitais, como as dos computadores, e não apenas com relação às fotografias e às imagens movimentadas, mas também aos textos digitalizados. Por outro lado, a percepção natural, particularmente o sistema visual - olhos, nervos óticos e partes interessadas do cérebro -, tem com o que o cerca um contato imagético, já que interpretamos como imagens as ondas eletromagnéticas captadas. A visão não enxerga o interior dos objetos (para tal precisaríamos do auxílio de aparelhos de radiologia ou de ressonância magnética), mas superfícies e volumes. Vemos imagens, tanto quanto todo o sistema visual, se pudéssemos vê-lo, seria visto como imagem, e não apenas em seu suporte material (isto é, fisiológico), mas igualmente em seu caráter perceptivo. Portanto, podemos tratar como imagem todo o percurso solidário entre o objeto percebido e a própria percepção (BERGSON, 1990). A imagem, assim, ganha um estatuto propriamente material e, não obstante, universal, como nos propõe Henri Bergson, já que imagem é matéria, luz ou movimento: só há imagens por toda parte (BERGSON, 1990). E as fotografias seriam extensões das imagens materiais, imagens de imagens, cuja originalidade residiria em todas as variantes que rodeiam a captura.

Idealmente, isto é, caso a memória não se imiscuísse na percepção (algo raríssimo, na maior parte das vezes a memória substitui a percepção), teríamos um contato puramente material com o que nos cerca. Tal é o nível imediato dessas fotografias, esse primeiro contato, quando o senso formal da fotógrafa, propriamente estético, procura recriar o mundo pela materialidade exacerbada dos enquadramentos, pela proximidade com os objetos retratados e pelo forte contraste.

Esse é o primeiro movimento. No entanto, o empreendimento se perderia caso não recorresse ao segundo movimento, de dimensão ética, pela qual transparecem dilemas e impasses propriamente sociais. Um movimento, de todo modo, evocativo.

Mas, o que evocam essas fotografias que tenho sob meus olhos? Elas apelam à memória, solicitam leituras, suscitam sentimentos, sensações, julgamentos morais, traços de pensamentos. Algo se passa em mim quando 


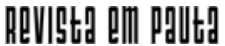

\} NOTAS SOBRE DEZ FOTOGRAFIAS - CARVALHO, M.; SILVA, T. \}

DOI: $10.12957 /$ REP.2020.47195

as vejo, um estremecimento. Já não me coloco como extensão do mundo material, onde todos os pontos do universo se correspondem e se afetam mutuamente (BERGSON, 1990), mas transito por códigos com os quais tento compreender traços daquilo que chamamos de "real", esfera que me convida a elaboração de um discurso a partir de índices e referências (DUBOIS, 2006), o que inclui as conexões legais e sociais. Uma dimensão social começa a se apresentar a mim.

O denominador comum em todas as dez fotografias é a encenação. Se todas as imagens são instantâneas e não posadas, os corpos retratados que ocupam as ruas, flagrados em ato, constroem cenários e neles performam. Tudo se passa pela encenação identitária e pela ritualização reivindicatória sobre cotidianidades opostas - a da violência contra as populações negras e a da religiosidade diaspórica africana - enquanto diferentes experiências de luta e de resistência.

Em uma das fotografias há pessoas com as mãos amarradas, portando alvos como se estivessem no interior de um estande de tiro, subjugadas ao mesmo tempo em que desafiam seu algoz. Outra imagem destaca um estandarte com o número 80 pintado em vermelho, em evidente referência a quantidade de tiros disparados por militares do Exército contra o automóvel do músico Evaldo dos Santos Rosa em uma rua de um subúrbio carioca, matando-o em frente a sua família. E na terceira fotografia, vemos mulheres com punhos levantados e segurando cartazes com fotografias e nomes de jovens assassinados pela repressão do Estado (Parem de Nos Matar, manifestação contra a política de segurança étnico-seletiva do governador Wilson Witzel, 2019, Copacabana). Ainda como parte desse mesmo conjunto de enfrentamento da violência étnica, duas outras fotografias remetem à vereadora Marielle Franco, cujo assassinato até hoje segue não completamente esclarecido. Em uma delas, mulheres negras levantam o braço com o punho cerrado e calçando luvas negras nas mãos em gesto que remete aos Panteras Negras, grupo norte-americano que luta contra a segregação racial e pelos direitos civis das populações afrodescendentes dos EUA. Na outra fotografia, as mesmas referências, tendo como fundo a escadaria da Câmara dos Vereadores do Rio de Janeiro. Em ambas as fotografias percebe-se uma clara diversidade de gênero (ato Um Ano sem Marielle, 2019, Cinelândia).

$\mathrm{O}$ outro conjunto de fotografias remete ao universo religioso. Em uma delas, um homem aponta o dedo ameaçadoramente a um oponente fora do enquadramento enquanto outro homem ri ao fundo, ambos personificados como a entidade de Umbanda seu Zé Pelintra (Marcha contra a Intolerância Religiosa, 2019 (evento anual), de Copacabana ao Leme). Duas outras fotografias referem-se à ritualística das religiões de matriz africana, a Lavagem com água de cheiro do Cais do Valongo, sítio arqueológico próximo à Praça Mauá, no Rio de Janeiro, onde acredita-se ter existido o principal porto de entrada dos africanos no país. O local foi elevado à Patrimônio Mundial da Humanidade pela Unesco em 2017. Em ambas as fotografias, as 


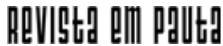

\} NOTAS SOBRE DEZ FOTOGRAFIAS - CARVALHO, M.; SILVA, T. \}

DOI: $10.12957 /$ REP.2020.47195

vestimentas e os paramentos dos religiosos e seus rostos e posturas corporais dão gravidade à cerimônia (Lavagem do Cais do Valongo, 2019 (evento anual), região do Cais do Porto do Rio de Janeiro). As duas últimas fotografias, formalmente as mais ousadas, trazem adeptos de lemanjá em sua festa anual (Homenagem à lemanjá, 2017 (evento anual), procissão do Cais do Valongo à Praça Mauá).

Há um debate bastante conhecido sobre o problema da figuração das imagens do holocausto nazista contra os judeus durante a Segunda Guerra Mundial. Claude Lanzmann, autor do filme Shoah (1985), é categórico ao se colocar contra a exibição das imagens do holocausto. Seu filme foi realizado inteiramente sobre depoimentos dos sobreviventes, sem utilização de imagens de arquivo que fotógrafos e cineastas das tropas aliadas fizeram ao chegarem aos campos de extermínio. O horror do holocausto, a gratuidade colocada em marcha por uma maquinaria industrial de matança, e que atingiu igualmente a outros grupos sociais como os ciganos, os homossexuais etc., seria de tal ordem inimaginável que as imagens precisariam sofrer uma interdição (estética e moral), sendo vedado o uso. Por outro lado, Georges DidiHuberman (2012), instado por quatro fotografias realizadas clandestinamente em Auschwitz-Birkenau por um membro do Sonderkommando (tropa auxiliar da SS que atuava nos campos de extermínio nazistas), exibidas na mostra Mémoire des Camps: Photographies des Camps de Concentration et d'Extermination Nazis (1933-1999), ataca a posição de Lanzmann, acusandoa de ser um interdito ao dever imperioso de ver (e produzir conhecimento) a partir das imagens sobre tais acontecimentos.

Evidentemente, não nos cabe entrar nessa discussão em um espaço de poucas linhas. Mas é notável que o Brasil, tendo experimentado vários genocídios ao longo de sua história, não tenha até agora produzido discussões mais amplas, para além da academia ou de iniciativas incipientes do Estado, discussões que não repetissem os mesmos termos referentes ao holocausto judeu sob o nazismo - a dicotomia entre o figurável e o interdito é fruto de outro contexto -, mas que iniciassem um processo de ressignificação de nosso próprio passado.

É difícil calcular o número de afrodescendentes e de indígenas mortos ou reduzidos a escravos pela ação direta do avanço europeu sobre a África e as Américas entre os séculos XVI e XIX. A conta chega à casa dos milhões. Os africanos, quando não obtinham sucesso pelo motim no interior dos navios negreiros, resistiam pelo suicídio ou pela greve de fome. A violência acontece hoje de outras formas, por vezes escamoteada nas políticas de segurança pública de Estado ou realizada com a intimidação sobre a religiosidade de matriz africana. As formas de resistência, por sua vez, precisam encontrar os veículos de expressão apropriados. Que essas fotografias e tantos outros esforços em conjunto não sejam em vão. 


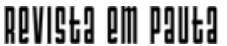

\} NOTAS SOBRE DEZ FOTOGRAFIAS - CARVALHO, M.; SILVA, T. \}

DOI: $10.12957 /$ REP.2020.47195

\section{Referências}

BARTHES, R. A câmara clara. Rio de Janeiro: Ed. Nova Fronteira, 2000.

BERGSON, H. Matéria e memória. São Paulo: Ed. Martins Fontes, 1990.

DELEUZE, G; GUATTARI, F. O que é a filosofia? Rio de Janeiro: Ed. 34, 1992.

DIDI-HUBERMAN, G. Imagens apesar de tudo. Lisboa: KKYM, 2012.

DUBOIS, P. O ato fotográfico. Campinas: Ed. Papirus, 2006.

DOI: $10.12957 /$ rep.2020.47195

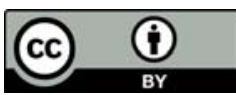

A Revista Em Pauta: Teoria Social e Realidade Contemporânea está licenciada com uma Licença Creative Commons Atribuição 4.0 Internacional. 


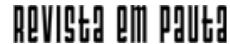

\} NOTAS SOBRE DEZ FOTOGRAFIAS - CARVALHO, M.; SILVA, T. \}

DOI: 10.12957/REP.2020.47195

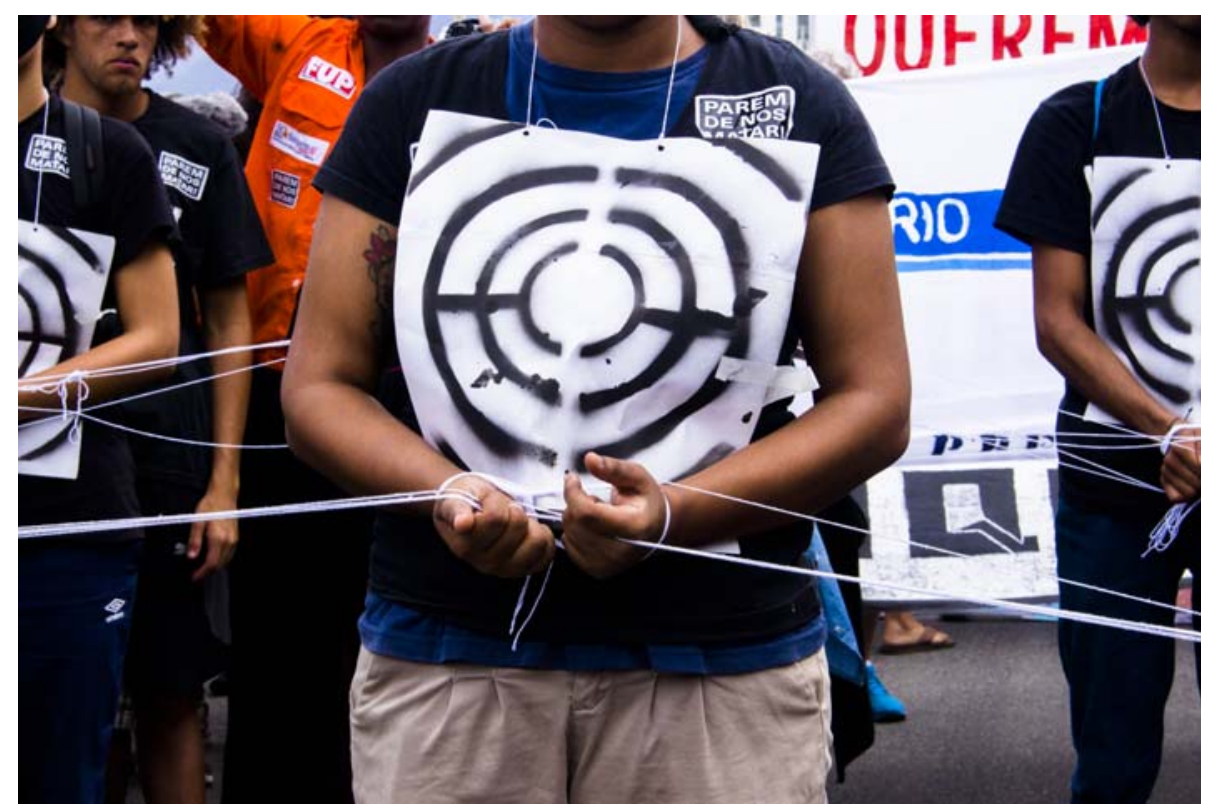

Manifestação Parem de nos matar, 2019 


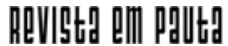

\} NOTAS SOBRE DEZ FOTOGRAFIAS - CARVALHO, M.; SILVA, T. \}

DOI: 10.12957/REP.2020.47195

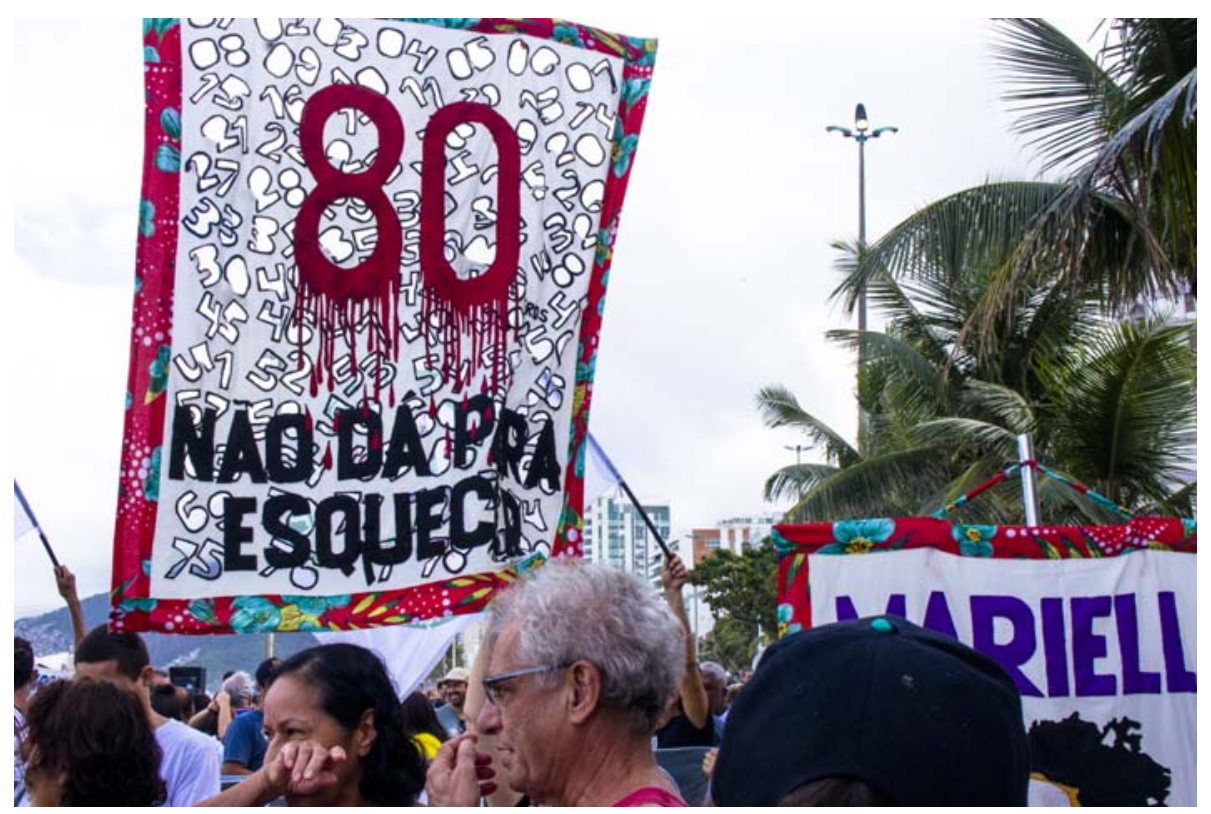

Manifestação Parem de nos matar, 2019 


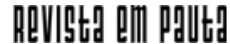

\} NOTAS SOBRE DEZ FOTOGRAFIAS - CARVALHO, M.; SILVA, T. \}

DOI: $10.12957 /$ REP.2020.47195

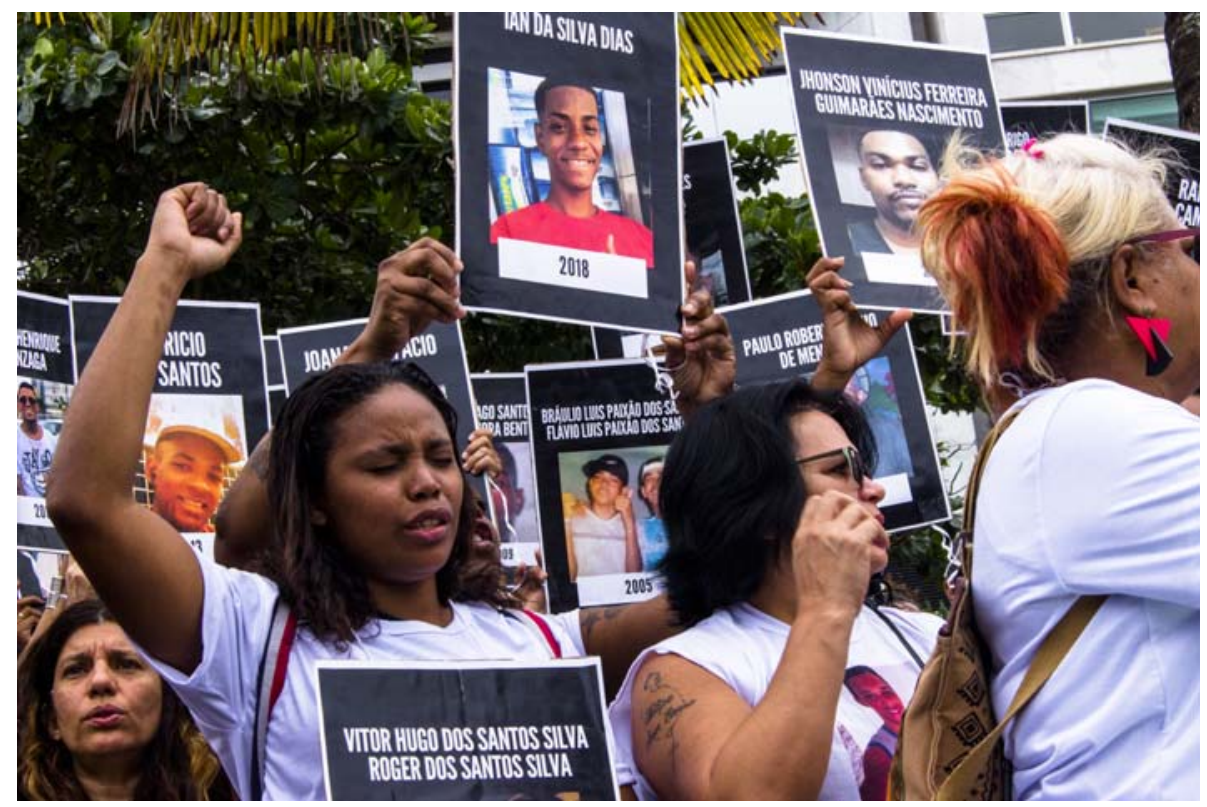

Manifestação Parem de nos matar, 2019 


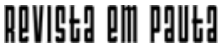

\} NOTAS SOBRE DEZ FOTOGRAFIAS - CARVALHO, M.; SILVA, T. \}

DOI: 10.12957/REP.2020.47195

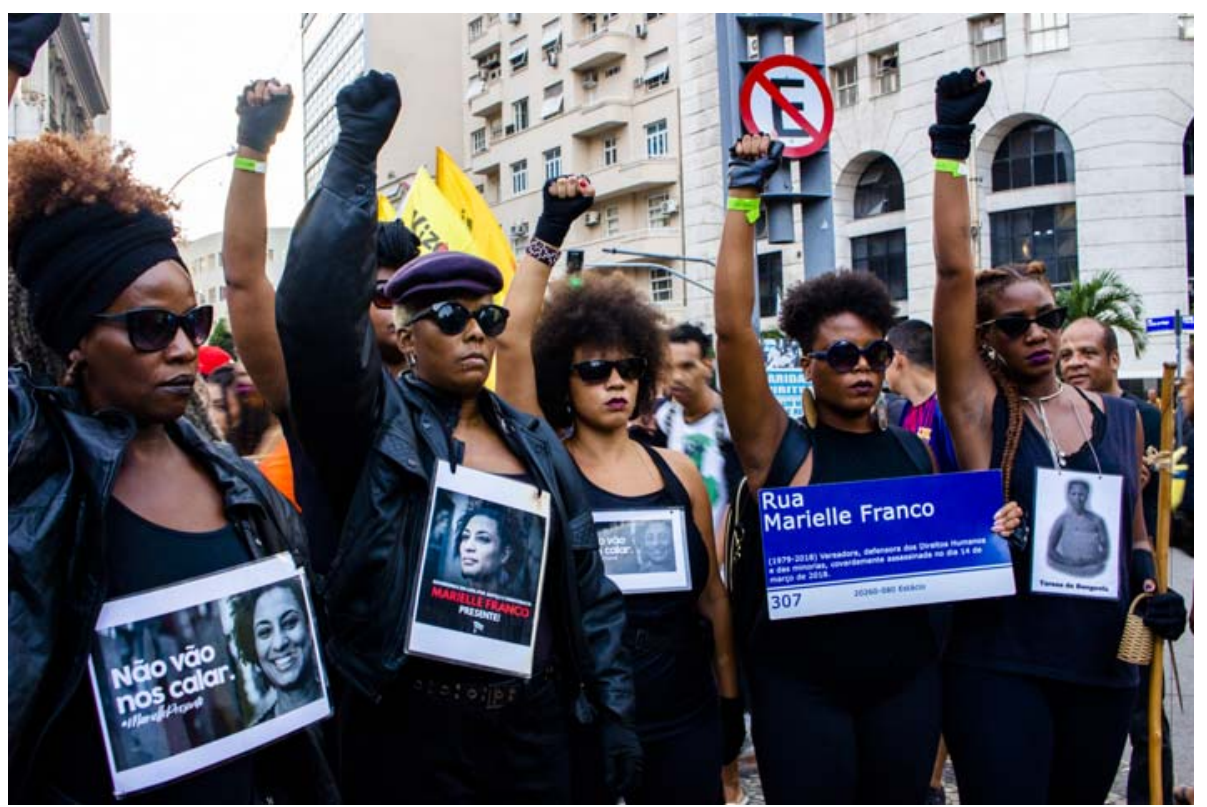

Um ano sem Marielle, 2019 


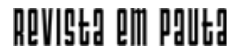

\{ NOTAS SOBRE DEZ FOTOGRAFIAS - CARVALHO, M.; SILVA, T. \}

DOI: $10.12957 /$ REP.2020.47195

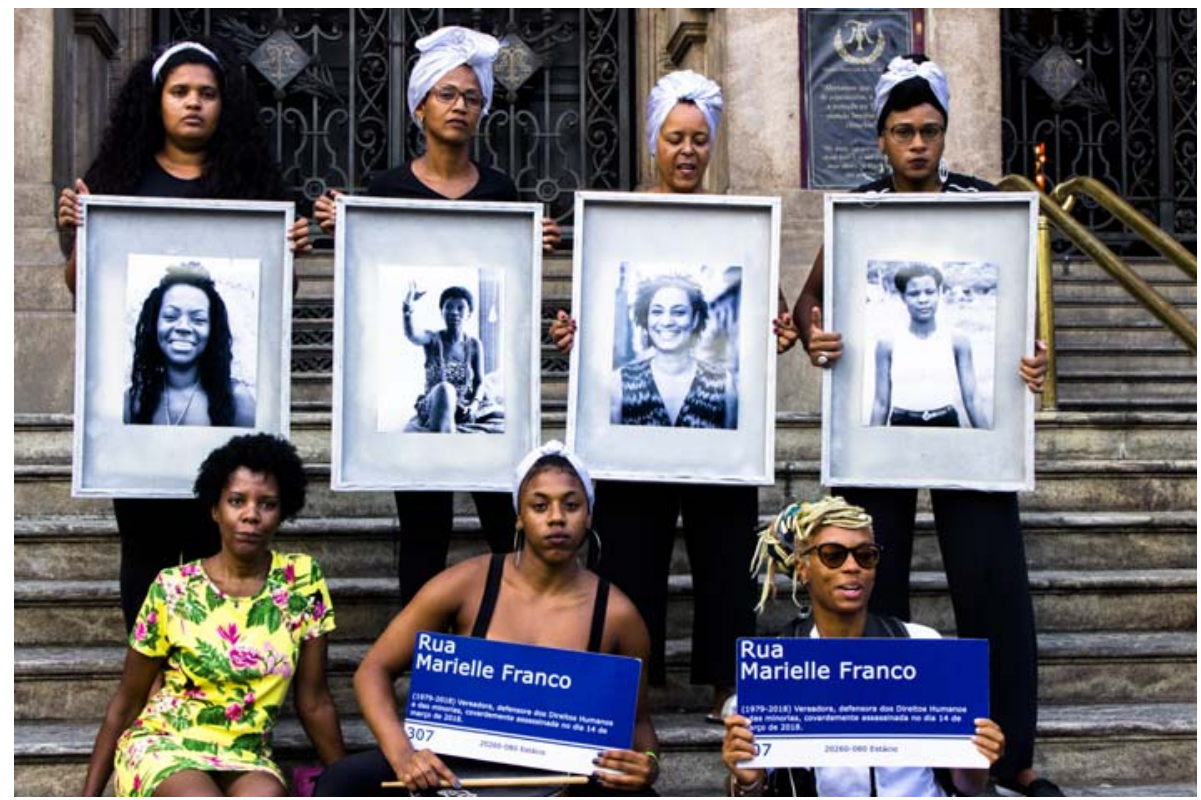

Um ano sem Marielle, 2019 


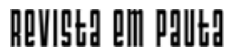

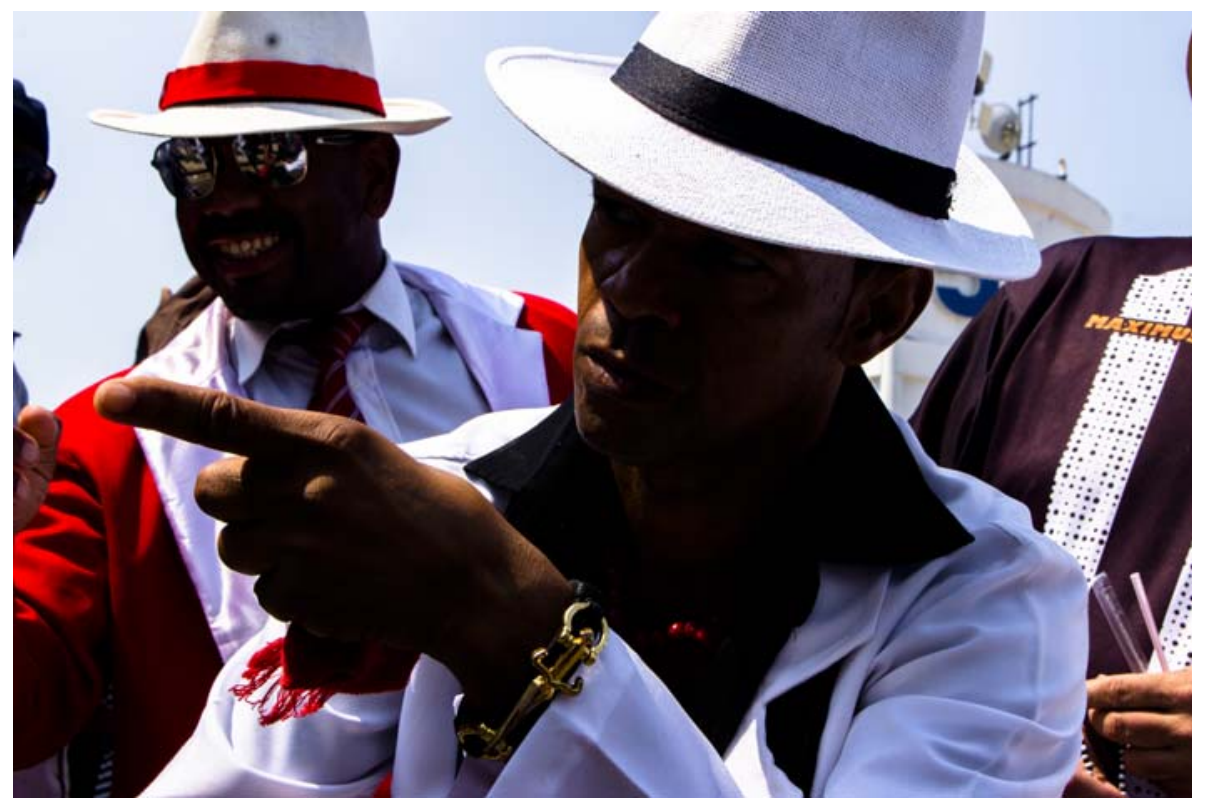

Marcha contra a intolerância religiosa, 2019 


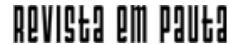

\} NOTAS SOBRE DEZ FOTOGRAFIAS - CARVALHO, M.; SILVA, T. \}

DOI: $10.12957 /$ REP.2020.47195

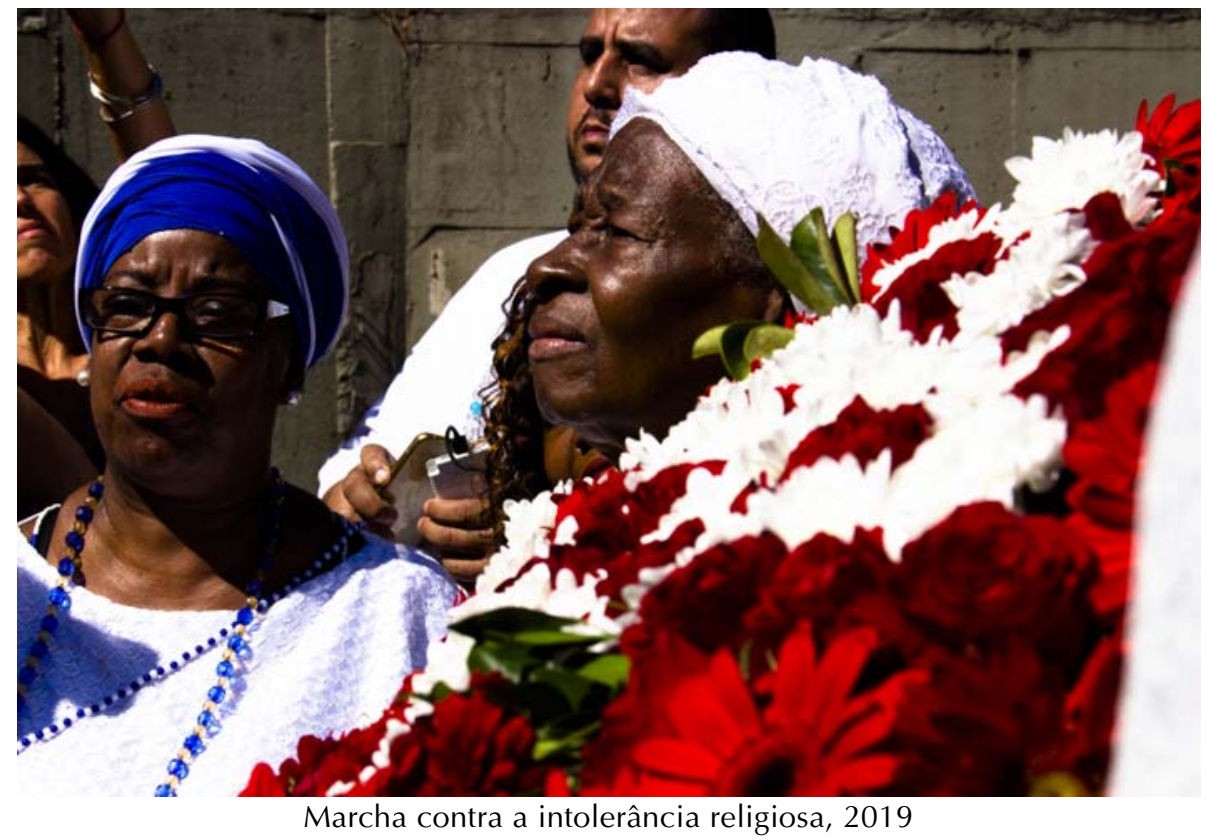




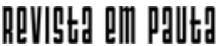

\} NOTAS SOBRE DEZ FOTOGRAFIAS - CARVALHO, M.; SILVA, T. \}

DOI: 10.12957/REP.2020.47195

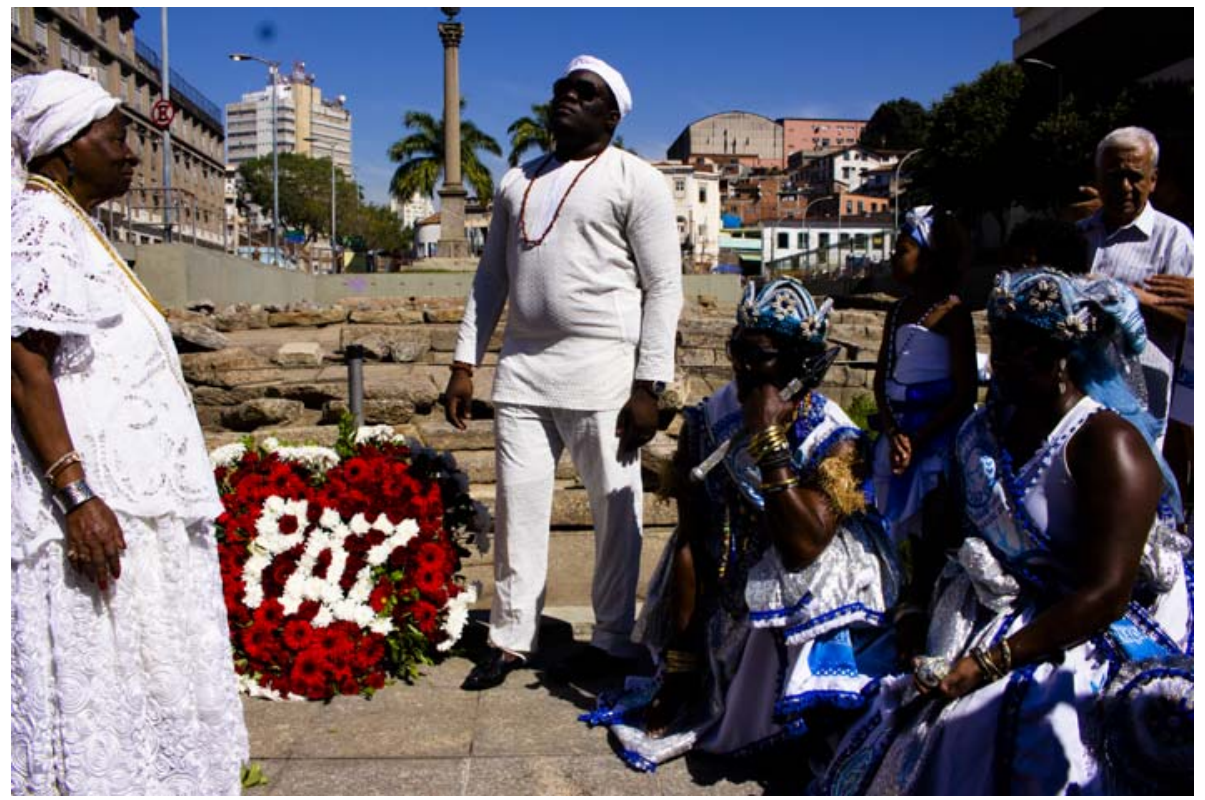

Lavagem do Cais do Valongo, 2019 


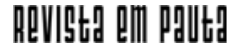

\} NOTAS SOBRE DEZ FOTOGRAFIAS - CARVALHO, M.; SILVA, T. \}

DOI: $10.12957 /$ REP.2020.47195

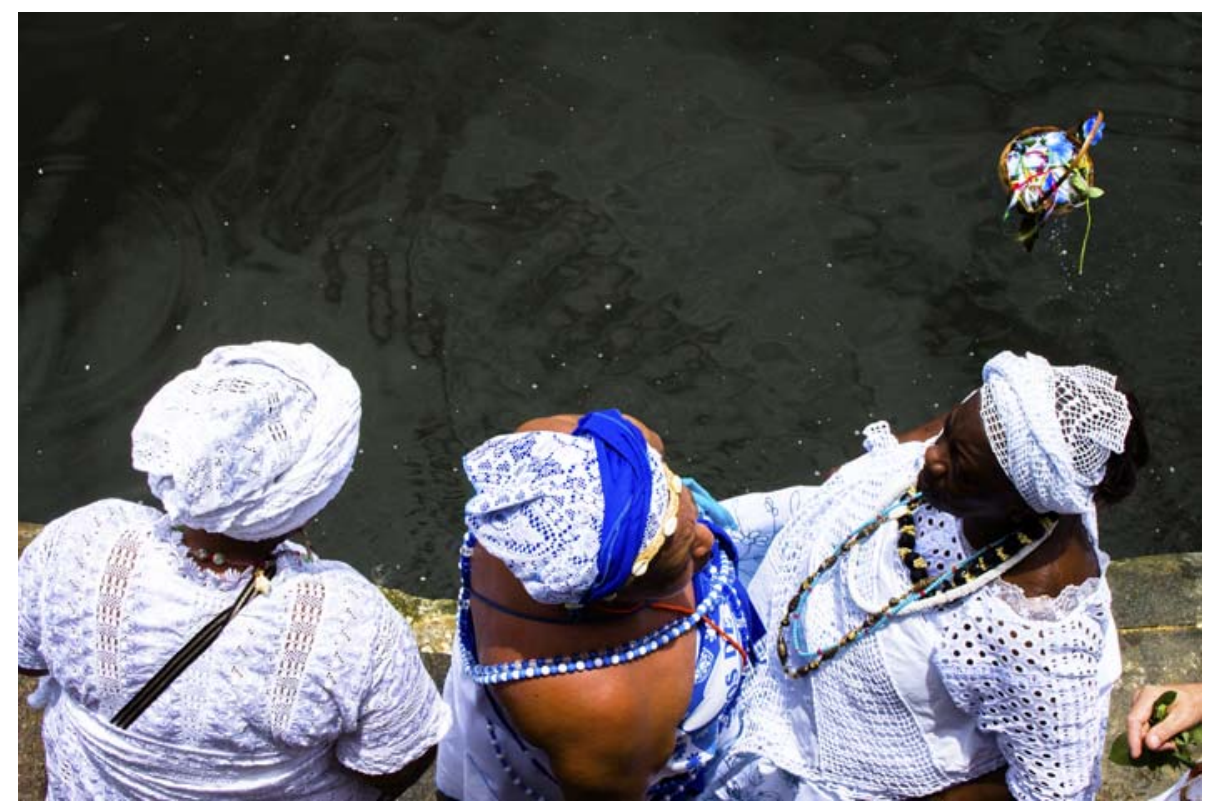

Homenagem a lemanja do Filhos de Gandhi, 2017 


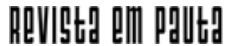

\} NOTAS SOBRE DEZ FOTOGRAFIAS - CARVALHO, M.; SILVA, T. \}

DOI: 10.12957/REP.2020.47195

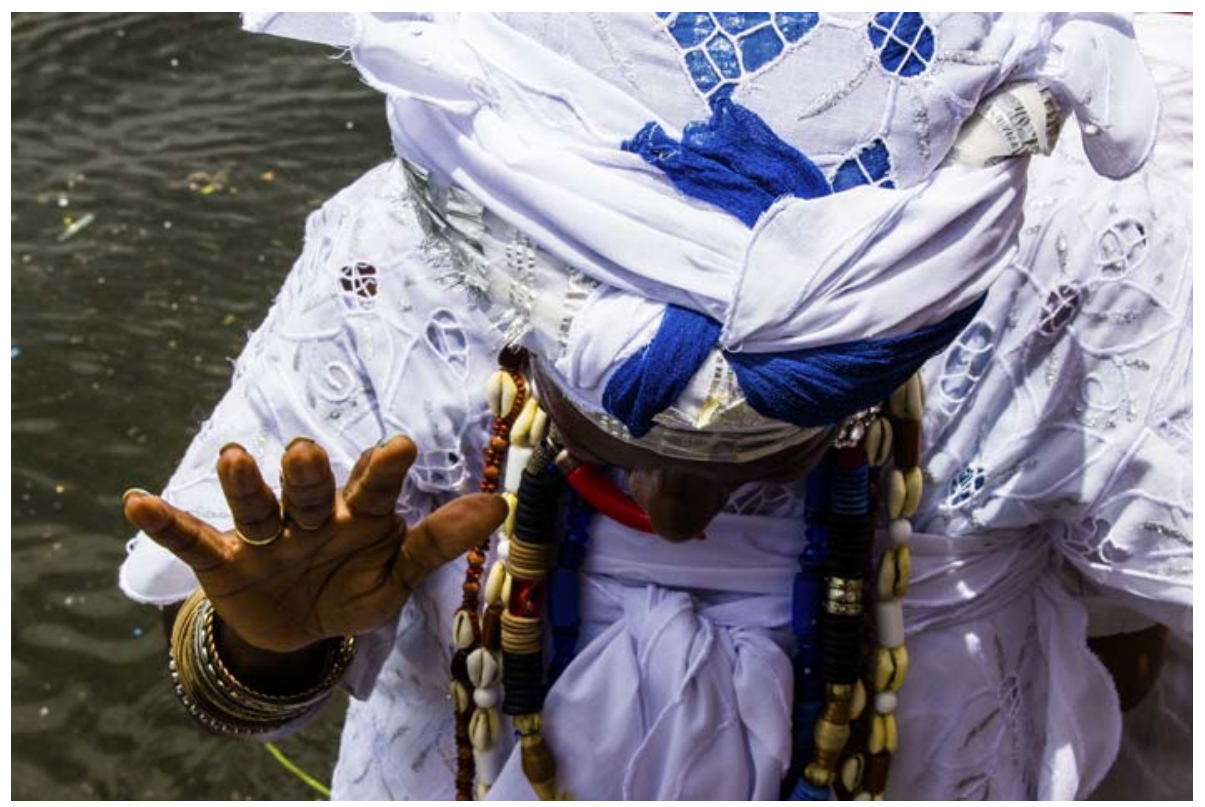

Homenagem a lemanja do Filhos de Gandhi, 2017 